\title{
O Corpo Disciplinado: Uma leitura de "Sargento Garcia" (1982), de Caio Fernando Abreu
}

Anselmo Peres Alós ${ }^{1}$

\begin{abstract}
The aim of this paper is analyzing the short-story "Sergeant Garcia", written by the Brazilian writer Caio Fernando Abreu and first published in 1982, in Moldy Strawberries. It is also important to mention that this paper is one of the partial results of the Research Project Contaminados, torturados, abjetos: por uma poética do corpo e da subjetividade na América Latina, granted by CNPq/Brazil (National Research Council). Using analytical tools from narratology, queer theory and gender studies, it is intended to demonstrate how Caio Fernando Abreus' fiction (specially the short-story "Sargento Garcia") simultaneously articulates a critique to the hegemonic masculinity regimes and the violence of the State in Brazil. Keywords: Homosexuality; Brazilian literature; Subaltern masculinities; Moldy Strawberries; "Sergeant Garcia”.
\end{abstract}

Resumo: O objetivo deste trabalho é analisar o conto "Sargento Garcia", de autoria do escritor brasileiro Caio Fernando Abreu, publicado pela primeira em Morangos mofados (1982). Cabe ressaltar ainda que este trabalho é um dos resultados parciais do projeto de pesquisa Contaminados, torturados, abjetos: por uma poética do corpo e da subjetividade na América Latina (2017-2019), que conta com o apoio financeiro do CNPq/Brasil (Conselho Nacional de Pesquisa). Usando ferramentas analíticas advindas da narratologia, da teoria queer e dos estudos de gênero, pretende-se demonstrar como a ficção de Caio Fernando Abreu (e, em especial, o conto "Sargento Garcia") simultaneamente articula uma crítica ao regime da masculinidade hegemônica e à violência estatal no Brasil.

Palavras-chave: Homossexualidade; Literatura brasileira; Masculinidades subalternizadas; Morangos mofados; "Sargento Garcia".

Para Rita Schmidt, por nossos diálogos; para Fábio Ramos, por nossos silêncios; e para Ana Flávia Souto de Oliveira, porque o novo sempre vem.

\section{Questões preliminares}

No cenário da literatura brasileira do século XX, provavelmente o nome de Caio Fernando Abreu seja aquele que mais frequentemente tenha sido associado à concretização

1 Doutor em Letras pela UFRGS. Professor Adjunto IV do Departamento de Letras Vernáculas da UFSM. 
de um projeto de ficção gay no Brasil, embora não seja o único (tampouco o primeiro) escritor a realizar deliberadamente tal projeto. Com uma produção extremamente profícua como contista, embora também autor de dois romances (Limite branco, seu livro de estreia, publicado em 1970, e Onde andará Dulce Veiga, publicado em 1990), é em 1982, com a publicação de Morangos mofados (pela Editora Brasiliense) que o autor ganha destaque e visibilidade em termos nacionais. $\mathrm{O}$ objetivo da discussão aqui proposta é realizar uma análise do conto "Sargento Garcia", um dos 17 contos que integra a obra Morangos mofados (1982), com vistas a realizar uma aproximação crítica e tentar compreender como se dá a estruturação e a constituição de diferentes regimes de masculinidade na enunciação da narrativa literária, articulando tal constituição com a questão da representação da(s) homossexualidade(s) no plano diegético da narrativa. Para tanto, serão recuperadas reflexões teóricas do campo dos estudos de gênero, dos gays and lesbian studies e da teoria queer, bem como das apropriações que a teoria literária (e, em especial, a narratologia) tem feito de tais estudos.

Os estudos gays e lésbicos emergem no mundo anglófono - particularmente na academia estadunidense - a partir do final da década de 1970, e institucionalizam-se ao longo da década de 1980. Essa emergência está relacionada às lutas das décadas de 1960 e 1970 nos Estados Unidos, no mesmo élan que permitiu a gênese da luta pelos direitos civis, das conquistas de movimento estudantil de 1968 e do feminismo internacional. Nota-se, nesse período de desenvolvimento e de institucionalização de tais discussões, uma grande influência da Histoire de la sexualité de Michel Foucault, em especial do primeiro volume (Histoire de la sexualité: la volonté de savoir. Paris: Gallimard, 1976). A sexualidade passa a ser vista não mais como um dado natural, mas como um dispositivo social de controle, atrelado às discussões em torno da biopolitica que produz subjetividades (Cf. FOUCAULT, 2008).

Em outras palavras, os discursos institucionalizados constroem a sexualidade: a medicina produz a noção de um corpo saudável em oposição à do corpo doente; a psiquiatria produz subjetividades normais em oposição às patológicas; a religião produz corpos ímpios em oposição aos crédulos, bem como o corpo virtuoso em oposição ao pecaminoso, e assim por diante. Para melhor controlar tudo aquilo que desestabiliza a ordem do Estado, uma lógica hierarquizante de classificação entra em ação: em outras palavras, melhor se conhece e melhor se domina aquilo que possui um nome e uma identidade. Trata-se de um conjunto de formações discursivas que produz, em diferentes momentos da história, diferentes regimes de verdade, que por sua vez gerenciam as sexualidades (tanto as legitimadas socialmente quanto aquelas que são classificadas como “desviantes"). Voltando à discussão no campo das representações postas em circulação pela literatura, pelo cinema e por outros artefatos culturais, pode-se afirmar que a literatura não apenas representa a sexualidade, mas que também a constrói.

No seu primeiro volume da Histoire de la sexualité, Foucault dá uma mostra de como o discurso estrutura identidades sexuais. Ao longo do século XIX, cristalizam-se quatro mitos, ainda segundo Foucault: a mulher histérica; o casal malthusiano, a criança masturbadora e o pervertido. Tais mitos sexuais consolidam-se a partir de um investimento discursivo que corporifica identidades e atribui valores sobre determinados corpos, saturando-os de significação. $\mathrm{O}$ corpo da mulher é visto como um corpo histérico, saturado de desmedidas e de furores, porque tais valores asseguram a manutenção das mulheres em um lugar subalternizado; o casal heterossexual demasiadamente prolífico é também visto como uma ameaça pelo Estado, que tem interesse em administrar o crescimento das populações no 
mesmo ritmo do crescimento das riquezas; o investimento de vigilância sobre os corpos das crianças, no que tange à masturbação, produz metonimicamente um controle sobre a sexualidade infantil, assegurando respectivamente um controle sobre o exercício da sexualidade fora dos parâmetros legais e religiosos do casamento; a figura do pervertido, por sua vez, satura de significados políticos os corpos daqueles indivíduos cujo exercício da sexualidade subverte, interfere ou não está na agenda de interesses de uma monogamia sexual controlada, no sentido de assegurar a manutenção e o crescimento das populações.

É a partir da figura do pervertido sexual e, em especial, do investimento da sexologia nascente no final do século XIX, que se estruturam "subjetividades pervertidas": o fetichista, o masturbador, a ninfomaníaca, o travesti e o sodomita, entre tantos outros.

A crítica literária, no campo dos estudos gays e lésbicos, muito deve aos postulados foucaultianos. Entre as obras que merecem destaque, nesse contexto, encontram-se o livro de Robert Drake, intitulado The gay canon: great books every gay man should read (1998). Partindo de um diálogo com O cânone ocidental (1995), de Harold Bloom, Drake propõe o estabelecimento de uma genealogia literária que rastreie a tradição de uma literatura gay na tradição ocidental. Sua proposta não é de realizar um revisionismo do cânone ocidental, mas sim a de mapear ao longo da história da literatura ocidental uma tradição paralela. De acordo com o autor:

The gay canon does not seek to achieve what Bloom abhors. Frankly, I stand in firm agreement with him that the Western canon should not be tempered with for reasons of minority bias. The gay canon seeks to exist outside the Western canon, touching upon it only where writers and works are in agreement. Yet The gay canon strives toward a goal similar to Bloom's: to isolate qualities that made these gay authors canonical - that is, authoritative in gay culture (DRAKE, 1998, p. XV-XVI).

Gregory Woods, também em 1998, publica um livro que terminou por se tornar uma das grandes referências no mundo anglófono acerca da discussão em torno de uma tradição literária gay. Em $A$ history of gay literature: the male tradition, Woods chama a atenção para o fato de que um continuum de obras produzidas ao longo da história e tomadas como um cânone de referência não é possível simplesmente a partir do trabalho de autores gays. Embora ele não inclua, em suas referências bibliográficas, o hoje clássico Les règles de l'art, de Pierre Bourdieu, sua visão acerca da constituição de uma tradição literária gay ao longo da história possui muitos pontos de contato com a ideia de Bourdieu de campo literário ${ }^{2}$. Woods mostra-se consciente de que não apenas os escritores e/ou os leitores produzem essa tradição, mas que a crítica e o mercado editorial possuem um papel decisivo na definição das obras que permanecem ao longo do tempo e das que acabem caindo no esquecimento da comunidade de leitores; ele também está atento ao fato de que os próprios movimentos de resgate e de releituras de obras olvidadas no passado interferem no processo de constituição de uma tradição literária:

2 Na verdade, Woods não inclui absolutamente nenhuma referência ao trabalho de Pierre Bourdieu ao longo de seu livro. Todavia, ele faz uma importante retomada do pensamento de Eric Hobsbawm, estruturando sua visão de construção de um cânone literário gay na esteira da noção de invenção das tradições. Segundo Hobsbawm, "what we are talking about here is homosexual men's deliberate creation of a homosexual tradition. Eric Hobsbawm's lucid introduction to his and Terence Ranger's book The invention of tradition is helpful here. Hobsbawm writes that traditions which appear or claim to be old are often quite recent in origin and sometimes invented" (WOODS, 1998, p. 4 - grifos do autor). 
The fact is that gay literature is not simply a matter of the emotional records of individual writes. Gay writers do not, on their own, 'make' gay literature. There are processes of selection, production and evaluation to be taken into account. Our canons of literature of quality are no more eternal than any other. Indeed, gay literary critics have been fairly explicit about the intentional social purposes behind their re-evaluations of past texts and canons. The contingencies behind the heralding of gay classics need to be acknowledged and made manifest. The canon of gay literature has been constructed by bookish homosexuals, most explicitly since the debates on sexuality and identity which flourished in the last third of the nineteenth century (WOODS, 1998, p. 3).

Robert W. Connell desenvolve, no campo da sociologia, a noção de masculinidade hegemônica, em oposição à de masculinidades subalternizadas. Connell define masculinidade como sendo "uma configuração de prática em torno da posição dos homens na estrutura das relações de gênero" (CONNELL, 1995b, p. 188), chamando a atenção para o fato de que, via de regra, simultaneamente coexistem "mais de uma configuração desse tipo em qualquer ordem de gênero de uma sociedade" (CONNELL, 1995b, p. 188). Em função dessa heterogeneidade de configurações que, simultaneamente, operam em uma sociedade, seria mais adequado falar em masculinidades, no plural, e não em uma concepção única e universal de masculinidade, no singular (CONNELL, 1995b, p. 188). Nesse conjunto de masculinidades plurais, haveria uma que se apresentaria como sua forma "hegemônica", aquela que corresponderia a um ideal cultural de masculinidade; paralelamente, ao lado desta forma socialmente privilegiada de masculinidade, existiriam outras que manteriam relações de subordinação, de cumplicidade ou de marginalização em relação à masculinidade hegemônica (CONNELL, 1997, p. 39-43), uma vez que sempre há uma modalidade de masculinidade que é hegemônica, valorizada e instigada em todo e qualquer contexto humano. Trata-se, no mundo ocidental, de uma masculinidade branca, heterossexual, burguesa e judaico-cristã. É a representação dominante da masculinidade, tomada muitas vezes como a própria definição de masculinidade. Em oposição a essa, há masculinidades outras, e que com essa primeira mantém uma relação de subalternidade: tratam-se das masculinidades racializadas, das masculinidades não cristãs, das masculinidades não heterossexuais, bem como das masculinidades orientalizadas, entre outras (CONNELL, 1987; CONNELL, 2000).

Algumas das categorias que usualmente são mobilizadas tanto pela crítica cultural e literária quanto pelo movimento social e que possuem algumas fragilidades são as de homoafetividade e homoerotismo. Essas categorias são frequentemente mobilizadas para tratar tanto da literatura escrita por homossexuais quanto da representação da homossexualidade na literatura (independentemente da orientação sexual dos autores em questão). Aqui se encontra o que me parece o ponto fulcral da questão, e que não raro é escamoteado pelos críticos:

a) a que(m) se aplica(m) o(s) adjetivo(s) homoerótico e/ou homoafetivo? Ao autor? Aos elementos formais? À temática? Ao leitor? À uma comunidade interpretativa?

b) Qual o (des)compromisso da crítica literária e cultural com os regimes sociais heteronormativos e homonormativos? 
Parece-me que enquanto tais pontos problemáticos não forem discutidos e teorizados pela crítica literária brasileira, o potencial crítico desse locus enunciativo sempre será minimizado no campo disciplinar mais amplo dos estudos literários.

Com relação à literatura de Caio Fernando Abreu e, em especial, com relação ao que vem sendo publicado acerca do conto "Sargento Garcia", as noções de homoafetividade e de homoerotismo também vêm sendo constantemente articuladas (por exemplo, BRAGA JÚNIOR, 2014, bem como PORTO, 2010). Entretanto, muitas vezes se esquece - deliberadamente ou não - que tais categorias analíticas surgem em dois contextos disciplinares bem específicos (homoafetividade é uma categoria oriunda do Direito de Família, enquanto homoerotismo é originária do campo da Psicanálise e da História da Arte), e que a utilização de tais categorias de maneira acrítica promove uma leitura rasa que se restringe meramente ao campo da representação, esquecendo-se não raro das próprias especificidades que caracterizam o trabalho intelectual no campo dos estudos literários. Ademais de tais questões, cumpre ressaltar que essas categorias apresentam algumas fragilidades já em seus campos disciplinares de origem, fragilidades estas que se acentuam por ocasião das tentativas de transplante das mesmas para o campo dos estudos literários.

A noção de homoafetividade ganhou particular popularidade no Brasil a partir do trabalho intelectual realizado nas searas jurídicas pela desembargadora sul-rio-grandense Maria Berenice Dias, mais especificamente no campo do Direito de Família. Tal categoria promoveu alguns avanços consideráveis no campo jurídico, como na legalização do casamento entre pessoas do mesmo $\mathrm{sexo}^{3}$, mas a um preço considerável: apagam-se e silenciam-se as vivências coletivas lésbicas e gays em nome de um arranjo familiar heteronormativo que toma como referência o modelo familiar nuclear, monogâmico e heterossexual ${ }^{4}$. Por que três lésbicas, por exemplo, não podem compartilhar a tutela de uma criança? Por que uma travesti (ou uma transexual female to male) não pode casar com duas lésbicas? Em outras palavras, a noção de homoafetividade coloca ainda mais à margem da legitimidade perante o Estado aqueles arranjos familiares que não se espelham em modelos heteronormativos nucleares e monogâmicos. A produção cinematográfica recente traz importantes problematizações dessas questões, e se pode mencionar, a título de exemplo, os filmes Cachorro $^{5}$ (Espanha, 2004, direção de Miguel Albaladejo), no qual um odontologista homossexual soropositivo perde a guarda do seu sobrinho para a avó paterna do mesmo, e Antonias Welt ${ }^{6}$ (Holanda, 1995, direção de Marleen Gorris), no qual um modelo familiar bastante alternativo mostra ao espectador uma família com um arranjo estrutural que não é pautado em laços consanguíneos, mas sim em laços de solidariedade e de sororidade. No contexto brasileiro, a produção cinematográfica que problematiza o modelo nuclear monogâmico do casamento heterossexual/heteronormativo mais conhecida provavelmente seja Eu tu eles (2000), dirigido por Andrucha Waddington, com roteiro de Elena Soarez. Baseado em uma história real, o filme ficcionaliza a história de

3 Desde 16 de maio de 2013, os cartórios brasileiros estão impedidos de recusar a celebração de casamentos civis de casais do mesmo sexo, ou deixar de converter em casamento a união estável homoafetiva, como estabelece a Resolução no 175, de 14 de maio de 2013, aprovada durante a $169^{\mathrm{a}}$ Sessão Plenária do Conselho Nacional de Justiça (CNJ).

4 Este argumento é extensivamente desenvolvido pela filósofa estadunidense Judith Butler, em Undoing gen$\operatorname{der}(2004$, p. 102-130).

5 Distribuído no Brasil sob o título Filhote.

6 Distribuído no Brasil sob o título A excêntrica família de Antônia. 
Maria Marlene da Silva Sabóia (no filme, a personagem Darlene), uma mulher humilde que protagoniza um "quadrângulo amoroso" com os três homens com quem vive.

A noção de homoerotismo, por sua vez, traz empecilhos teóricos de uma outra ordem. Popularizada no Brasil pelo psicanalista Jurandir Freire Costa como uma alternativa desatrelada do imperialismo da categoria gay, ela minimiza a questão dos aspectos políticos do movimento homossexual, reduzindo-a apenas à esfera do desejo sexual. A categoria homoerotismo, quando articulada por Costa em suas análises literárias, funcionou como uma resistência à categoria do sujeito homossexual, visto como um sujeito "desviante" ou "anormal" quando colocado em confronto com sujeito heterossexual (enquadrado nos termos de uma certa prática psicanalítica como o sujeito "normal"). O apelo de Costa à noção de homoerotismo também está ligada a uma recusa do autor de ver as práticas sexuais como determinantes da identidade humana. Em última análise, os estudos do psicanalista iam, no momento da primeira edição de A inocência e o vício (em 1992), ao encontro de uma crítica à construção de uma subjetividade gay ou homossexual como a contrapartida de uma natureza psíquica inerente aos sujeitos homossexuais. Segundo ele, práticas sexuais não seriam determinantes de subjetividades ou de identidades (COSTA, 1994) ${ }^{7}$.

Ao desvincular a experiência homossexual da esfera de uma subjetividade homossexual, como consequência, torna-se inviável a defesa de uma subjetividade homossexual como uma instância política de agenciamento. Todavia, as apropriações da categoria que têm sido realizadas por alguns pesquisadores no campo dos estudos literários violam o princípio básico da noção desenvolvida por Costa em $A$ inocência e o vício, chegando a extremos como o de insistirem na defesa da ideia de sujeitos homoeróticos ou de subjetividades homoeróticas, revelando uma misreading, uma "desleitura", ou ainda, uma leitura descontextualizada e equivocada do conceito cuja origem é alógena aos estudos literários ${ }^{8}$. Isso não implica em uma crítica à interdisciplinaridade, mas na defesa da ideia de que se deve ter redobrada atenção quando se articula conceitos de outras áreas, a fim de não promover a apropriação indébita e descontextualizada de categorias analíticas.

\section{O sargento e o recruta: iniciação, poder e violência simbólica}

"Sargento Garcia", um dos 17 contos publicados no volume Morangos mofados, de 1982, é talvez uma das mais emblemáticas e representativas narrativas escritas por Caio Fernando Abreu. Trata-se de um conto que possui traços de Bildungsroman. A narrativa conta a história da descoberta de si protagonizada pelo jovem Hermes (que, ademais de protagonista, também é o narrador que relata a história). Se é lícito afirmar que Morangos mofados é o mais conhecido dos livros do escritor gaúcho, talvez também o seja afirmar que "Sargento Garcia" é o mais conhecido dos contos da coletânea", a ponto de

7 Isso configura uma interessante tentativa de "des-essencializar" a homossexualidade; todavia, as categorias homoerótico e homoerotismo mais prometeram do que cumpriram, uma vez que passaram a ser utilizadas nas humanidades com sinônimos de gay ou homossexual e homossexualidade, mas de maneira despolitizada e descontextualizada das raízes e das agendas políticas do movimento gay no mundo ocidental pós-Stone Wall.

8 Ver, por exemplo, FERNANDES (2012), Configurações do desejo homoerótico na contística brasileira do século XX, e CARBONEL (2012), Homoerotismo e marginalização.

9 Poucos são os leitores que se recordam do enredo do conto que empresta o título à coletânea publicada em 1982, mas muitos são os que se recordam de Sargento Garcia (tanto do personagem quanto do conto homônimo). 
ter inspirado o curta-metragem Sargento Garcia (2000), dirigido por Tutti Gregianin ${ }^{10}$. A narrativa passa-se na cidade de Porto Alegre, na década de 1970 . O conto inicia-se na caserna militar, desenvolve-se no espaço aberto da cidade (embora dentro do Chevette do Sargento Garcia), e termina no cabaré/garçonière de Isadora. Todos esses espaços são, simultaneamente, espaços de intimidade e de repressão. $\mathrm{O}$ espaço claustrofóbico do conto ajuda a situar a narrativa no tempo histórico: o período dos anos de chumbo da Ditadura Militar Brasileira.

Hermes é um jovem pré-universitário que se encontra em pleno processo de descoberta de sua identidade sexual; Sargento Garcia é um militar, homem mais velho, másculo, de aspecto e trato rudes, que se tornará, no desenrolar do enredo, o responsável pela iniciação sexual de Hermes. A terceira personagem de destaque é Isadora/Valdemir, a travesti e administradora do bordel/garçonière onde o Sargento costuma levar seus jovens amantes. O bordel é também, para Hermes, o espaço iniciático no qual entrará em contato com os seus mais recônditos desejos.

O conto traz alguns elementos paratextuais deveras importantes para a realização de sua exegese. Caio Fernando Abreu dedica este conto à memória de Luiza Felpuda, famosa travesti de Porto Alegre que, entre 1960 e 1980, mantinha um bordel muito frequentado por militares, localizado nas cercanias do bairro Menino Deus. A personagem Isadora é, também, um tributo realizado pelo autor à memória de Luísa Felpuda, que morreu sob condições suspeitas em um atentado a bomba no início da década de 1980, tal como Paulo Heuser rememora na crônica "A rua"11.

Ao contrário de outros contos de Caio Fernando Abreu, como, por exemplo, "Aqueles dois", que também integra a coletânea Morangos mofados, este é um conto que poderia ser classificado como out of the closet. Se é verdade que um dos motes centrais do conto é o da iniciação sexual de um jovem com um homem mais velho, não se pode esquecer que esta narrativa trata, também, de temáticas como a violência e a opressão: Hermes não se opõe aos avanços sexuais do Sargento - pelo contrário, Hermes deseja a iniciação. Não se pode menosprezar, entretanto, o fato de que o iniciador (o personagem Sargento Garcia) é: (a) um militar; (b) cuja identidade de gênero se enquadra nas normas de uma masculinidade hegemônica, a despeito do exercício de sua sexualidade com outros homens.

Hermes, cujo encontro com o Sargento dá-se em função de seu alistamento para o cumprimento do Serviço Militar Obrigatório Brasileiro, é um jovem que está se preparando para o vestibular - como já mencionado anteriormente - e deseja cursar Filosofia,

10 O curta foi disponibilizado no Portal Curtas da Petrobrás. Disponível em: $<$ http://portacurtas.org.br/filme/?name $=$ sargento_garcia $>$. Acesso em: 06 de setembro de 2014.

11 "Eis que eu estava participando de um curso no Rio, quando meus colegas cariocas comentaram que havia ocorrido um atentado em Porto Alegre. Sem internet, só consegui notícias através dos jornais impressos. Após vasculhar alguns, encontrei a tão procurada notícia. Seria um atentado contra a OAB? Ou o alvo seria a imprensa? Nem um, nem outro. Ocorrera uma explosão na minha tão familiar Rua Caldas Júnior, quase na esquina com a [Rua] Riachuelo. Parecia obra de uma brigada moralista, pois o alvo fora uma casa de costumes, como se dizia na época. Lembro-me dela, por fora, bem entendido. Subitamente, no meio da madrugada, uma imensa explosão lançou pela janela o cidadão, cujo nome não lembro, cuja alcunha não esqueço. Pois o vivente usava o codinome Luísa Felpuda. Não havia como esquecê-lo, não é? Luísa Felpuda alçara vôo, estatelando-se no meio da Caldas Júnior. Assim como a funcionária Lydia Monteiro da Silva, da OAB do Rio, Luísa Felpuda, da Caldas Júnior, morreu. Involuntários personagens de eventos isolados de explosões, que tiveram o mesmo fim". Disponível em: $<$ http://pauloheuser.blogspot.com.br/2006/12/rua. html >. Acesso em: 02 de setembro de 2018. 
ao que tudo leva a crer, na Universidade Federal do Rio Grande do Sul. Sargento Garcia, por sua vez, é um militar que se autodefine "mais grosso do que dedo destroncado"12 (ABREU, 1995, p. 84), que foi "colocado nos eixos" (ABREU, 1995, p. 84) pela dureza da vida cotidiana do Exército Brasileiro. Durante o trajeto entre o quartel e a garçonnière administrada por Isadora, Hermes faz uma referência à obra de Leibniz e às mônadas, na ocasião de Sargento Garcia lhe pergunta: "me conta, qual é a tua filosofia de vida?" (ABREU, 1995, p. 84). Frente à resposta evasiva e à referência às mônadas, Sargento Garcia responde: "pra te falar a verdade, eu aqui não entendo desses troços. Passo o dia inteiro naquele quartel, com aquela bagualada mais grossa que dedo destroncado. E com eles a gente tem é que tratar assim mesmo, no braço, senão te montam pelo cangote e a vida vira um inferno" (ABREU, 1995, p. 84). Como resposta à referência de Hermes a Leibniz, Sargento Garcia responde: "minha filosofia de vida é simples: pisa nos outros antes que te pisem. Não tem dessas mônicas daí" (ABREU, 1995, p. 84). Apesar dos universos que parecem impossíveis de ser conciliados, o narrador pondera e afirma que Leibniz poderia estar errado, e que talvez haja a possibilidade de se estabelecer "pontes": "podia haver pontes entre as mônadas, pensei. E mordi a ponta da língua” (ABREU, 1995, p. 85).

Há importantes aspectos alegóricos que permeiam esta narrativa. Trata-se de uma história sobre a violência e o desejo projetados pelos militares sobre os estudantes - e nisso o conto é uma emblemática narrativa dos tempos ditatoriais dos anos de chumbo ${ }^{13}$. O aspecto político que não raro é escamoteado pelos críticos sobre este conto (e este é, de longe, um dos contos mais citados e estudados de Caio Fernando Abreu) é a tematização - ainda que de forma ligeiramente velada - da violência militar consolidada no Brasil. Embora não se configure como um elemento explicitamente explorado no plano da diegese, não se pode esquecer que Hermes, como estudante e futuro candidato ao vestibular em Filosofia, pode ser lido metonimicamente como o corpo da sociedade civil brasileira da época, enquanto a figura do Sargento Garcia pode ser associada ao corpo político do regime de exceção instaurado no Brasil com a "Revolução de 64" (o Golpe de Estado Civil-Militar que instaura a Ditadura no Brasil, e que se estende até 1985).

Ainda no campo das duas personagens principais em torno das quais a trama do conto é construída, Hermes pode ser lido como referência à figura mítica do Panteão Olímpico: na antiga tradição grega, Hermes é o deus da comunicação e do comércio, protetor dos ladrões e dos mercadores. Hermes é uma divindade de beleza andrógina, e algumas versões do mito grego colocam Hermes e Afrodite como os genitores de Hermafrodito, uma divindade menor cujo corpo é fundido ao da ninfa Salmacis (essa versão está presente nas Metamorfoses, de Ovídio). A androginia do Hermes Olímpico (a divindade, não o protagonista do conto de Abreu) não deve ser confundida com aquela que perpassa o mito da antiga raça dos andróginos, presente em O banquete, de Platão. Tais referências ao mundo clássico e à filosofia platônica são bastante pertinentes para a exegese do conto, uma vez que é em $O$ banquete, através da referência ao mito dos andróginos, que surge uma das primeiras tentativas de se explicar a gênese do amor homossexual.

O termo cronotopo foi empregado pela primeira vez por Albert Einstein, no contexto das suas formulações acerca da Teoria da Relatividade, no campo da física teórica.

12 Neste trabalho, cito o conto a partir da edição de 1995, publicada pela Companhia das Letras.

13 Conferir, acerca do contexto dos anos de chumbo da Ditadura Militar Brasileira, o trabalho de Elio Gaspari (2002a, 2002b, 2003 e 2004). 
Mikhail Bakhtin, em Questões de literatura e de estética: a teoria do romance (2002), retoma o conceito, reformulando-o e tornando-o produtivo para a análise do gênero narrativo - em especial o romance - no campo dos estudos literários. De acordo com Bakhtin,

[...] no cronotopo artístico-literário, ocorre a fusão dos indícios espaciais e temporais em um todo compreensivo e concreto. Aqui o tempo condensa-se, comprime-se, torna-se artisticamente visível; o próprio espaço intensifica-se, penetra no movimento do tempo, do enredo e da história. Os índices de tempo transparecem no espaço, e o espaço reveste-se de sentido e é medido com o tempo. Esse cruzamento de séries e a fusão de sinais caracterizam o cronotopo artístico (BAKHTIN, 2002, p. 211).

Um pouco mais adiante, na mesma obra, Bakhtin sublinha a estreita e pertinente relação entre os gêneros literários e seus respectivos cronotopos, a ponto de afirmar que "as variedades de gênero [textual e literário] são determinadas pelo cronotopo" (BAKHTIN, 2002 , p. 212). Um dos cronotopos recorrentes nas narrativas que versam sobre os amores entre homens é o dos espaços caracterizados como fechados, claustrofóbicos e - não raro - repressivos. Nesse sentido, o espaço da caserna (como em Bom-Crioulo, de Adolfo Caminha), o da prisão (como em El beso de la mujer araña, de Manuel Puig), o do internato (como em $O$ ateneu, de Raul Pompeia), ou mesmo o do seminário (como no romance Em nome do desejo, de João Silvério Trevisan) são recorrentes, em especial nas narrativas brasileiras, podendo ser notados também em um contexto mais amplo, na história do romance latino-americano de fins do século XIX e do século XX. Outra constante que pode ser identificada é a representação da homossexualidade não como uma identidade em perspectiva essencialista, mas como constructo resultante de aprendizagem e de negociações entre homens. Na esteira dessas afirmações, seria bem mais interessante e criticamente produtivo pensar o conto não através das lentes do homoerotismo, mas sim através das lentes que se preocupam com os pactos homossociais (SEDGWICK, 1989).

A temática do desejo emerge no conto a partir de uma visão telúrica, como se pode observar pela recorrência de imagens orgânicas e viscosas, ligadas ao imaginário dos subterrâneos da intimidade. Como exemplos, pode-se mencionar a descrição do bigode do Sargento, que Hermes compara a um maranduvá: "começava a odiar aquele bigode grosso como um maranduvá cabeludo rastejando em volta da boca, cortina de veludo negro entreaberta sobre os lábios molhados" (ABREU, 1995, p. 77). Maranduvá (corruptela de marandová) é uma palavra utilizada, em diversas regiões do Brasil, mas principalmente na região sul, para designar as formas larvais de várias espécies de mariposas, em especial daquelas cujas larvas possuem o corpo recoberto de pelos urticantes. A comparação do bigode de Sargento Garcia a um marandová, metaforicamente, associa a sensação de uma queimadura urticante aos pelos faciais, o que pode ser lido sintomaticamente como desejo, mas também como um desejo que é da ordem daquilo que envolve algum tipo de risco ou de perigo. Os corpos dos colegas na caserna que, como Hermes, estão completamente nus em função do processo de alistamento nas forças do Exército Brasileiro, exalam um cheiro pungente que se mistura ao cheiro do estrume dos cavalos: "muito perto, cheiro de suor de gente e cavalo, bosta quente, alfafa, cigarro e brilhantina. Sem mover a cabeça, senti seus olhos de cobra percorrendo meu corpo inteiro vagarosamente" (ABREU, 1995, p. 78).

Estes índices narrativos dão o tom de como será a iniciação sexual de Hermes: marcada pela brutalidade, pela instauração de hierarquias e pelo uso da força, características 
que marcam não apenas as relações entre homens na esfera pública, mas que, aqui, são deslocadas para a esfera do privado, da vida íntima e do boudoir:

O cheiro azedo dos lençóis, senti, quantos corpos teriam passado por ali, e de quem, pensei. Tranquei a respiração. Os olhos abertos, a trama grossa do tecido. Com os joelhos, lento, firme, ele abria caminho entre as minhas coxas, procurando passagem. Punhal em brasa, farpa, lança afiada. Quis gritar, mas as duas mãos se fecharam sobre a minha boca. Ele empurrou, gemendo. Sem querer, imaginei uma lanterna rasgando a escuridão de uma caverna escondida, há muitos anos, uma caverna secreta. Mordeu minha nuca. Com um movimento brusco de corpo, procurei jogá-lo para fora de mim.

- Seu puto - ele gemeu. Veadinho sujo. Bichinha-louca (ABREU, 1995, p. 90).

Os códigos arregimentados que pautam as relações sociais entre homens, dentro de uma concepção hegemônica de masculinidade heterossexual, não são apenas preservados no pacto social estabelecido entre Hermes e Sargento Garcia no espaço público, mas deslocados e transmutados em uma estrutura que servirá de diretriz para a efêmera relação que será estruturada por ambos em torno do desejo recíproco:

Agarrei o travesseiro com as duas mãos, e num arranco consegui deitar novamente de costas. Minha cara roçou contra a barba dele. Tornei a ouvir a voz de Isadora que mais me podes dar que mais me tens a dar a marca de uma nova dor. Molhada, nervosa, a língua voltou a entrar no meu ouvido. As mãos agarraram a minha cintura. Comprimiu o corpo inteiro contra o meu. Eu podia sentir os pelos molhados do peito dele melando a minha pele. Quis empurrá-lo outra vez, mas entre o pensamento e o gesto ele juntou-se ainda mais a mim, e depois um gemido mais fundo, e depois um estremecimento no corpo inteiro, e depois um líquido grosso morno viscoso espalhou-se pela minha barriga. Ele soltou o corpo. Como um saco de areia úmida jogado sobre mim (ABREU, 1995, p. 90).

\section{Considerações finais}

Se as histórias de amor heterossexual foram utilizadas como alegorias que faziam parte de um projeto burguês de promoção de uma hegemonia nacional, cabe perguntar: que tipo de interferência é produzida por estas outras histórias de amor nos imaginários nacionais? As reflexões em torno da mentalidade hetero e do contrato heterossexual (WITTIG, 2002) possibilitam a formulação de algumas inquietantes questões: as maneiras pelas quais se produz conhecimento não estariam encobrindo algum tipo de interesse? Quando uma feminista, uma afrodescendente ou um homossexual reivindicam legitimidade para produzir conhecimento a partir de seus próprios pontos de vista, são acusados de proselitismo, de comprometimento ideológico, de falta de rigor científico, até mesmo de obscurantismo. Mas de onde surge este discurso que acusa todos os "não brancos", "não homens" e "não heterossexuais" de "não universais" e de "politicamente comprometidos"?

O pressuposto que sustenta tal argumento é o de que um lugar neutro e universal, do ponto de vista da produção de conhecimento, não estaria contaminado por interesses políticos e particularistas. Cabe perguntar, pois, em nome de quem o universalismo e a neutralidade falam: seriam eles - o universalismo e a neutralidade - posições isentas de "contaminação política", de "interesses" e de "subjetivismo", ou seriam apenas posições 
que pretendem velar suas implicações ideológicas? Ou, como questiona Judith Butler, “who devises the protocols of 'clarity' and whose interests do they serve? What is foreclosed by the insistence on parochial standarts of transparency as requisite for all communications? What 'transparency' keeps obscure?” (BUTLER, 1999, p. XIX).

O que está em jogo quando os regimes heteronormativos são questionados e subvertidos, mas as assimetrias referentes às relações de gênero são mantidas e subscritas? Pensar a literatura e as artes a partir de um locus identitário declinado pela homossexualidade masculina pode ser caracterizado como um modo queer de se produzir conhecimento $^{14}$. Contudo, ignorar o papel que as assimetrias de gênero tomam nessas materialidades artísticas implicaria em reduzir a dinâmica do poder de uma matriz heteronormativa a uma oposição binária heterossexualidade $v s$. homossexualidade, tomando como válida a hipótese repressiva que o próprio Michel Foucault refutou no primeiro volume de sua História da sexualidade. Por isso a importância de se manter em mente as ressalvas feitas por Kathy Rudy. Em "Radical feminism, lesbian separatism and queer theory"15, Rudy celebra as conquistas do pensamento queer em reabilitar algumas posturas frente à pornografia e ao sadomasoquismo, por exemplo. Entretanto, salienta os perigos de se cair em uma armadilha ao se adotar cegamente as benesses de posturas políticas em um mundo excessivamente pós-identitário: "the struggle to recover women and to move beyond them emerges as an agenda which can offer a better world for people of all sexual and gender identifications. This version of queer theory understands finally that without feminism, queer theory will simply be another fight among boys" (RUDY, 2001, p. 221).

\section{Referências}

ABREU, C. F. Limite branco. Rio de Janeiro: Expressão e Cultura, 1970. . Morangos mofados. 1. ed. São Paulo: Brasiliense, 1982. Morangos mofados. 9. ed. São Paulo: Companhia das Letras, 1995. Onde andará Dulce Veiga? São Paulo: Companhia das Letras, 1990.

$\overline{\mathrm{ALO}}$, A. P. A autoria feminina e a literatura brasileira no século XIX: novas perspectivas sobre a literatura indianista e a representação do embate colonial. In: BRASIL. Secretaria Especial de Políticas para as Mulheres (Org.). $1^{\circ}$ Prêmio Construindo a Igualdade de Gênero. Brasília: Secretaria Especial de Políticas para as Mulheres, 2006a. p. 118-143. . A letra, o corpo e o desejo: masculinidades subversivas no romance latino-americano. Florianópolis: Mulheres, 2013.

. A literatura comparada neste início de milênio: tendências e perspectivas. Ângulo, Lorena, a. 35, n. 130, jul.-set. 2012a, p. 7-12.

. Corpo e gênero no romance oitocentista brasileiro: uma leitura de Bom-Crioulo, de Adolfo Caminha. Terra roxa e outras terras, Londrina, v. 15, jun. 2009b, p. 16-25.

. Gênero, epistemologia e performatividade: estratégias pedagógicas de subversão. Estudos Feministas, Florianópolis, v. 19, n. 2, 2011a, p. 421-449.

. Heterotopias hipertextuais: escrevendo mundos digitais em La ansiedad e keres $\overline{\text { kojer }}=$ guan tu fak. Ipotesi, Juiz de Fora, v. 14, n. 1, jan.-jul. 2010, p. 69-80.

14 Alguns trabalhos que seguem essa linha de investigação são os de ALÓS (2006, 2008, 2009a, 2009b, 2011a, 2011b, 2012a, 2012b, e 2013). Ver também ALÓS e ALÓS (2011).

15 Publicado em Feminist Studies. v. 27, n. 1, Spring, 2001. p. 190-222. 
. Literatura comparada ontem e hoje: campo epistemológico de ansiedades e incertezas. Organon, Porto Alegre, v. 27, n. 52, 2012b, p. 17-42.

. Madame Satã e a encenação do feminino: impasses de um malandro travestido de vermelho. Gênero, Niterói, v. 8, n. 2, $1^{\circ}$ sem. 2008, p. 369- 385.

. Prolegomena queer: gênero e sexualidade nos estudos literários. Cadernos de Letras da UFF, Niterói, n. 42, 2011b, p. 199-217.

. Um exercício comparatista da leitura queer: reflexões em torno d'El beso de la

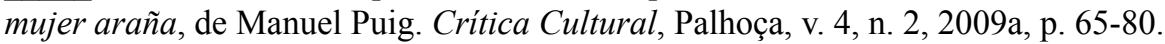

ALÓS, A. P.; ALÓS, I. P. Dos direitos humanos ao direito constitucional: a questão das uniões homoafetivas. Bagoas, Natal, v. 5, n. 6, 2011, p. 157-179.

BAKHTIN, M. Questões de literatura e de estética: a teoria do romance. São Paulo: Annablume, 2002.

BOURDIEU, P. Les règles de l'art: genèse et structure du champ littéraire. Paris: Seuil, 1992.

BRAGA JÚNIOR, L. F. L. Caio Fernando Abreu: narrativa e homoerotismo. Curitiba: Appris, 2014.

BLOOM, H. O cânone ocidental. São Paulo: Objetiva, 1995.

BUTLER, J. Gender trouble. $10^{\text {th }}$ Anniversary Edition. London, Routledge, 1999. Undoing gender. London: Routledge, 2004.

CAMINHA, A. Bom-crioulo. São Paulo: Ática, 1995.

CARBONEL, T. I. Homoerotismo e marginalização. Araraquara: UNESP, 2012. (Tese de doutorado).

CONNELL, R. W. Gender and power. Stanford: Stanford University Press, 1987.

La organización social de la masculinidad. In: VALDÉS, T. y OLIVARRÍA, J. (Comp.). Masculinidad/es: poder y crisis. Santiago: Ediciones de las Mujeres, 1997, p. $31-48$

. Masculinities. Berkeley: University of California Press, 1995a.

Políticas da masculinidade. Educação \& realidade, v. 20, n. 2, 1995b, p. 185-206.

The men and the boys. Berkeley: University of California Press, 2000.

Theorizing gender. Sociology, n. 19, v. 2, 1985, p. 260-272.

CONNELL, R. W.; MESSERSCHMIDT, J. W. Hegemonic masculinity: rethinking the concept. Gender \& Society, v. 19, n. 6, 2005, p. 829-859.

COSTA, J. F. A ética e o espelho da cultura. Rio de Janeiro: Rocco, 1994.

. A inocência e o vício. Rio de Janeiro: Relume-Dumará, 1992.

DRAKE, R. The gay canon: great books every gay man should read. New York: Anchor Books, 1998.

FERNANDES, C. E. A. Configurações do desejo homoerótico na contística brasileira do século XX. Campina Grande: UEPB, 2012. (Dissertação de mestrado).

FOUCAULT, M. Histoire de la sexualité. Paris: Gallimard, 1976.

. Nascimento da biopolítica: curso no Collège de France (1978-1979). São Paulo:

Martins Fontes, 2008.

GASPARI, E. A ditadura derrotada. São Paulo: Companhia das Letras, 2003. A ditadura encurralada. São Paulo: Companhia das Letras, 2004. A ditadura envergonhada. São Paulo: Companhia das Letras, 2002a. A ditadura escancarada. São Paulo: Companhia das Letras, 2002b.

HOBSBAWM, E.; RANGER, T. (Editors). The invention of tradition. Cambridge: Cam- 
bridge University Press, 1983.

MISKOLCI, R. E. O desejo da nação. São Paulo: Annablume, 2013.

OVIDE. Les métamorphoses. Paris: Les Belles Lettres, 1955 (3 volumes).

PLATÃO. O banquete. Trad. José Cavalcante de Souza. 5. ed. São Paulo: Nova Cultural, 1991.

POMPEIA, R. O ateneu. 16. ed. São Paulo: Ática, 1996.

PORTO, L. T. Morangos mofados: crítica social e melancolia. Porto Alegre: Editora da UFRGS, 2010.

PUIG, M. El beso de la mujer araña. New York: Vintage Books, 1994.

RUDY, K. Radical feminism, lesbian separatism and queer theory. Feminist Studies. v. 27, n. 1, Spring, 2001. p. 190-222.

SEDGWICK, E. K. Between Men. New York: Columbia University Press, 1985.

TREVISAN, J. S. Em nome do desejo. 3. ed. São Paulo: Record, 2001.

WITTIG, M. The straight mind and other essays. Chicago: Beacon Press, 2002.

Recebido em: 11/12/2018; Aceito em: 30/12/2018 